\title{
A comparison of the early reading strategies of isiXhosa and Setswana first language learners
}

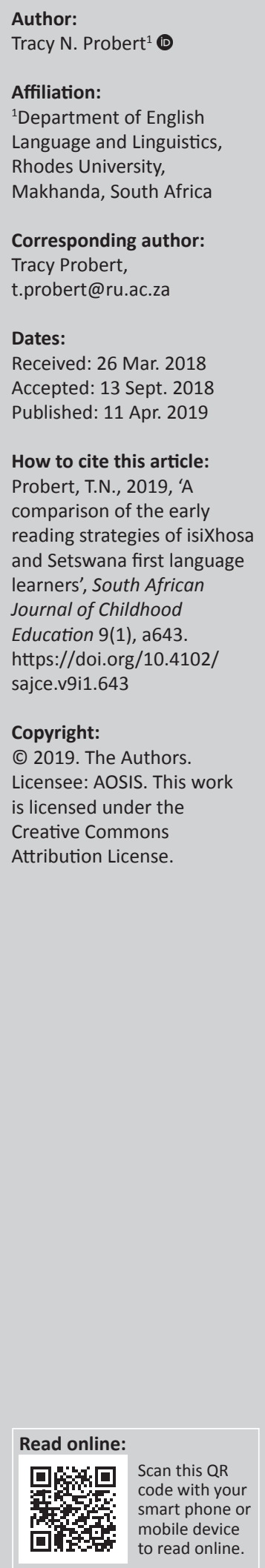

Background: A large amount of evidence highlights the obvious inequalities in literacy results of South African learners. Despite this, a sound understanding of how learners approach the task of reading in the African languages is lacking.

Aim: This article examines the role of the syllable, phoneme and morpheme in reading in transparent, agglutinating languages. The focus is on whether differences in the orthographies of isiXhosa and Setswana influence reading strategies through a comparative study of the interaction between metalinguistic skills and orthography.

Setting: Data was collected from Grade 3 first-language and Grade 4 Setswana homelanguage learners attending no fee schools in the Eastern Cape and North West Province respectively.

Methods: Learners were tested on four linguistic tasks: an open-ended decomposition task, a phonological awareness task, a morphological awareness task and an oral reading fluency task. These tasks were administered to determine the grain size unit which learners use in connected-text reading.

Results: The results indicated that syllables were the dominant grain size in both isiXhosa and Setswana, with the use of morphemes as secondary grains in isiXhosa. These results are reflected in the scores of the metalinguistic tasks.

Conclusion: This research contributes to an understanding of how linguistic and orthographic features of African languages need to be taken into consideration in understanding literacy development.

Keywords: early literacy; reading strategies; isiXhosa; Setswana; grain size in word recognition; metalinguistic skills; conjunctive versus disjunctive orthography.

\section{Introduction}

South African education continues to be crippled by a literacy crisis. This is highlighted by ongoing school literacy evaluations. For example, according to the most recent Progress in International Reading Literacy Study (Howie et al. 2017), 78\% of South African Grade 4 learners do not have basic reading skills and are at least 6 years behind the top performing countries, with 8 in 10 children unable to read for meaning (Howie et al. 2017). Reading performance in the African languages was particularly low, with $90 \%$ of Grade 4 learners tested in Setswana unable to read for meaning, with a similarly large percentage in isiXhosa learners, $88 \%$ (Howie et al. 2017). This has implications for later academic success for these learners, as they are constantly playing catch-up and this further entrenches inequalities in early literacy, which are evident in the current literacy results. The sources of the problem of the literacy crisis are multifaceted, with the majority of the studies on educational inequality focusing on social, historical and political issues. ${ }^{1}$ In addition, there are linguistic dimensions that need to be considered, such as the unique structure of the Southern Bantu languages, the different writing systems which they employ and decoding challenges associated with these orthographies. This is important in that the type of linguistic unit that best predicts successful reading depends on the language and the characteristics of the orthography in which children are learning to read (Goswami 2002; Ziegler et al. 2010), which, in turn, has pedagogical implications for early reading instruction.

One of the reasons why South African readers are listed as some of the poorest in the world (Howie et al. 2008, 2012, 2017) is that very little is known about how reading works in the African languages. Attempts at reducing inequalities through literacy depend to a large extent

1.Readers are directed to Heugh (2000), Pretorius and Mokwesana (2009), Tebekana and Cishe (2015) and van Staden and Bosker (2014) for more on the specific macro-factors which are faced by children in South Africa. 
on understanding the factors that promote success in reading in these languages. Appropriate pedagogical methodologies which are based on the unique features of the African languages will prove immensely advantageous for improving literacy levels and empowering speakers of these languages.

\section{Orthography and word structure in isiXhosa and Setswana}

IsiXhosa and Setswana fall within the Southern Bantu language family, more specifically the Nguni language group (which includes isiXhosa, isiZulu, isiNdebele and SiSwati) and the Sotho language group (Setswana, Southern and Northern Sotho), respectively. The Southern Bantu languages ${ }^{2}$ in South Africa are agglutinating languages with mostly transparent orthographies. A word in the Southern Bantu languages includes rich, overt morphology. Nouns include noun class prefixes as well as stems, whereas verbs include morphological reflexes of subject marking, object marking, tense, aspect, mood, causativity and negation amongst others (Nurse \& Phillipson 2003). Therefore, what is said to constitute a word in the Southern Bantu languages (specifically in the Nguni languages) tends to be much longer than what would be said to constitute a word in English:

(1) (a) star (English)

inkwenkwezi (isiXhosa)

NC9.star

(b) to use (English)

$\sim$ ukusebenzisa (isiXhosa)

INF.use.CAUS.FV

Furthermore, linguistic structure is mediated through orthography (Probert \& De Vos 2016). Both isiXhosa and Setswana are agglutinating languages containing long, multimorphemic words; however, the Sotho group tends to have a disjunctive orthography, ${ }^{3}$ while the Nguni group has a conjunctive orthography. The examples below show that in isiXhosa, the morphological word coincides with the orthographic word (2a), but that in Setswana, the morphological word is represented by several orthographic words in that blank spaces are placed between the morphemes that make up the word ( $2 b)$. The morphological word refers to the piece of speech which behaves as a unit of pronunciation as well as meaning in context, and as a domain for linguistic procedures, while the orthographic word refers to a written sequence bounded by spaces at each end (Trask 2004). It is the correspondence between orthographic and morphological words which distinguishes conjunctive orthographies from disjunctive orthographies:

2.The use of the term 'Bantu" is an internationally accepted term to refer to the Bant language group within the Niger-Congo language family. It is not used to refer to people as occurred during the apartheid regime. It is acknowledged that the use of the term 'Bantu' has derogatory connotations in lay usage within the Republic of South Africa, but it is used here in its technical linguistic sense.

3.There are examples where in Sotho, some things are written conjunctively, for example, O nthagile (translated as, 'He kicked $\mathrm{me}^{\prime}$ ), where the object marker is written conjunctively with the verb.
(2) (a) Ndiyababona

SM1.SG.PRES.OM2.see.FV ${ }^{4}$

'I see them' (isiXhosa)

(one morphological word and one orthographic word)

(b) Ke a ba bona

SM1.SG.PRES.OM2.see.FV

'I see them' (Setswana)

(one morphological word and four orthographic words)

When learning to read, a reader is faced with languagespecific processing challenges when attempting to recognise words in a particular language which, in turn, presupposes language-specific reading strategies. This leads one to the question of how readers unpack words in the Southern Bantu languages where the notion of what constitutes a 'word' differs across the different language groups. This is important for reading instructional methods and materials, as there is no one-size-fits-all approach to fluent reading across languages (Probert \& De Vos 2016).

Current methods used to teach reading in the African languages often fail to consider the unique linguistic characteristics of these languages (Probert \& De Vos 2016). Much of the current instructions used in South African classrooms is borrowed from the teaching of early reading in English (Pretorius \& Spaull 2016). This is not necessarily the best way to teach early reading in African languages, given that the writing systems of the African languages are different to that of English, as illustrated in (1) and (2). English is an analytic language with an opaque orthography, whereas the African languages are agglutinating with transparent orthographies. Linguistic differences and similarities between English and the African languages which influence aspects of reading are seldom dealt with in teacher training programmes (Pretorius \& Spaull 2016). Therefore, there is a lack of applied knowledge about how best to teach reading in the African languages, which is informed by linguistic principles. Furthermore, there is a complete absence of research on how differences in the disjunctive and conjunctive writing systems might engender different reading profiles or developmental trajectories, which has pedagogical implications for how best to teach reading in agglutinating African languages.

\section{Word recognition, orthography and metalinguistic skills}

The term 'metalinguistic skill' refers to the 'ability to identify, analyse and manipulate language forms' (Koda 2007:2). The two metalinguistic skills under investigation in this study are morphological awareness and phonological awareness. Morphological awareness is the readers' conscious awareness of the morphemic structure of words and their ability to reflect on and manipulate the meaningful parts of words (Kirby et al. 2012; McBride-Chang et al. 2005). Phonological

4.Glossing: SM1. sg: Subject marker Noun Class 1. sg. pres: present tense marker OM2: Object marker Noun Class 2. See: verb root. fv: final vowel. 
awareness is the awareness that words can be broken down into units so that one can manipulate the individual sounds and syllables, which may not have meaning (Anthony \& Francis 2005; Chard \& Dickson 1999; Stahl \& Murray 1994).

A number of studies have demonstrated that phonological awareness plays a fundamental role in reading success in alphabetic orthographies (Bradley \& Bryant 1985; Castles \& Colheart 2004; Stanovich, Cunningham \& Cramer 1984). Phonological awareness is especially important in the early stages of literacy acquisition, when the regularity of phoneme-to-grapheme correspondence helps the reader recognise or decode new words. Wilsenach (2013) and Diemer, van der Merwe and de Vos (2015) show the significance of phonological awareness for reading in Northern Sotho and isiXhosa, respectively. In particular, Diemer et al. (2015) showed that learners perform much better at syllable awareness tasks than they do at phoneme awareness tasks. It must be acknowledged that while the syllabic nature of African languages might contribute to high levels of syllable awareness, this is not the only contributory factor. Children tend to do better at syllable awareness tasks than phoneme awareness ones as phoneme level tasks are more difficult. Therefore, younger children master syllable awareness more easily than phoneme awareness (Perfetti 1994; Shankweiler \& Fowler 2004; Wilsenach 2013). In addition to this, phoneme awareness is influenced by learning of letter-sound relationships. It is for this reason that phoneme awareness generally correlates with reading success more than syllable awareness (Diemer 2015; Cunningham 1989; Godoy, Pinheiro \& Citoler 2017). Furthermore, reading in the early years cannot be divorced from its classroom context. For example, much of what passes for early instruction in African language classrooms is the chanting of syllabic 'ba-be-bi-bo-bu' patterns of sounds. Learners are therefore very tuned into syllables. It is unsurprising that they do better on syllable-related tasks, given the syllabic nature of the African languages, but how does it impact on word and/or sentence reading?

Similarly, there is evidence that morphological awareness promotes literacy development in both early (Casalis \& Louis-Alexandre 2000) and later literacy (Carlisle 2000), with correlations with comprehension, spelling and vocabulary (Carlisle 2003, 2000; Land 2015) and fluency scores (Rees 2016; Saiegh-Haddad \& Geva 2007). Linking prefixes, suffixes and base words with an understanding of their meaning and function helps the reader recognise familiar words and access meaning (Carlisle \& Stone 2005). Given the distinct morphological character of the Southern Bantu languages, the Bantu verb is of particular interest. Rees (2016) found a significant relationship $(r=0.61, p<0.0001)$ between morphological awareness and oral reading fluency (ORF) when she assessed 74 isiXhosa Grade 3 learners. According to her, having an explicit awareness of morphemes may help in processing the structure of agglutinating words while reading. This should, in practice, lead to comprehension in reading as readers rely on reading meaningful grain sizes. But to what extent does an awareness of the morpheme influence reading strategies? This has implications for early reading instruction and development, given that the different language groups' orthographies reflect morphological features in different ways.

Although evidenced in the literature that phonological awareness and morphological awareness are important for alphabetic literacy acquisition, what remains unclear is how the characteristics of orthography (conjunctivism vs. disjunctivism) and their relationship with the spoken language influence the development of literacy (Durgunoğlu \& Öney 1999). This is highly relevant given that the linguistic features of a language are reflected in its writing system. For example, the presence of phonological processes of vowel coalescence and elision in the Nguni language group make the use of a disjunctive script impractical (Louwrens \& Poulos 2006). This is illustrated in example (3) below where two vowels ' $a$ ' and ' $u$ ' in sequence coalesce into ' $\mathrm{o}$ ', making disjunctive transcription at odds with the phonetic pronunciation (Probert \& De Vos 2016).

\section{(2) Utata na umama}

$\rightarrow$ realised as: utata nomama

father and mother

According to Mattingly (1992:14), this is why the reader must acquire awareness of those linguistic features and he suggests that the orthography itself determines which aspects of representation are singled out for awareness. Both morphological and phonological features of the Southern Bantu language orthographies are thus relevant to the process of learning to read (Trudell \& Schroeder 2006).

Word recognition is a foundation skill for reading (Aaron et al. 1999; Invenizzi \& Hayes 2010; Snowling \& Hulme 2005) and involves retrieving information about the spoken form and meaning of a word from its written form (Invenizzi \& Hayes 2010; Snowling \& Hulme 2005). Previous psycholinguistic studies have shown that word recognition can be influenced by orthography (Scholfield \& Chwo 2005; Simon \& Van Herreweghe 2010). Much of the research on word recognition and its interaction with orthography is guided by the orthographic depth hypothesis (ODH), originating with Katz and Frost (1992b). According to this hypothesis, the reading process is different for users of different orthographies, and these differences are usually because of their differing morphology and phonology. Readers of a shallow orthography rely more on phonological encoding - direct phoneme-to-grapheme mappings - whereas readers in a deep orthography rely more on orthographic processing - most likely a wholeword mapping. This 'strong' version of the ODH, however, gave way to a weaker version as it became apparent that readers of shallow orthographies rely not only on graphemeto-phoneme correspondences but are also able to use the stored phonology from the lexicon, particularly when approaching unfamiliar or less transparent words (Katz \& Frost 1992a; Probert \& De Vos 2016). The weak ODH makes provision for the use of lexical decoding strategies by 
readers of shallow orthographies, as well as for the use of phoneme-to-grapheme mappings in deep orthographies. However, readers of deep orthographies cannot rely on phoneme-to-grapheme strategies alone (Probert \& De Vos 2016). According to the hypothesis, the type of linguistic unit (grain size) that best predicts successful reading depends on the language and the characteristics of the orthography that children are learning (Goswami 2002; Share 2008).

The psycholinguistic grain size theory (PGST) was established to build upon the assertions of the ODH. 'Grain size' refers to the literacy processing units learners use to unpack words when reading (i.e. through the use of whole words, syllables, morphemes or phoneme-to-grapheme mappings). The PGST proposes that because languages vary in the consistency with which the phonology is represented in the orthography, there are developmental differences in the grain size of lexical representations (Ziegler \& Goswami 2005). Differences in reading accuracy and reading speed found across orthographies reflect fundamental differences in the nature of phonological recoding and reading strategies that are developing in response to the orthography (Ziegler \& Goswami 2005). The process of learning to read across different languages and orthographies involves a system of mapping the correspondences between symbols and sounds (Share 1995; Ziegler \& Goswami 2006). Orthographies vary only in the degree to which they represent these. Alphabetic orthographies primarily aim at sequential representation of phonemes, but they also reflect linguistic features on the syllabic or morphemic level (Cook \& Bassetti 2005).

The PGST describes the way in which a novice reader builds up the connections between print and speech at the very start of reading acquisition. The PGST explains that readers must solve three problems, phonological availability, orthographic granularity and consistency in order to learn to read. Children initially read by identifying larger units (i.e. the syllable) before smaller units (i.e. the phoneme). This is in line with the hierarchy model of word recognition (Anthony \& Lonigan 2004; Scheule \& Boudreau 2008; Ziegler \& Goswami 2005). Research amongst Spanish readers aged 6-7 years has shown that languages with a simple phonological structure and a consistent orthographic representation display a lower association between phonemic awareness and reading, and higher associations between syllable awareness in early reading (Tolchinsky \& Jisa 2017). This was attributed to the simplicity and saliency of the Spanish syllable structure and vowel system, which is reinforced by the consistency of the Spanish orthography. Learners were found to be significantly less proficient in phoneme isolation than in syllable deletion and were able to achieve reading success in Spanish without being able to explicitly segment words into phonemes (Tolchinsky \& Jisa 2017). This accounts for a greater role that syllables play in reading at initial stages of literacy acquisition (Carraeiras \& Perea 1998; Jiménez \& Ortiz 2000). Readers of more phonologically transparent writing systems are therefore more likely to use strategies which focus on letterphoneme conversion, and/or syllables (Cook \& Bassetti
2005) than strategies of whole-word recognition or morpheme recognition when attempting to read at a young age.

The transparent nature of the Southern Bantu languages would thus yield the successful use of phonological decoding, in particular for correct pronunciation of the words, but it will not necessarily result in access to meaning. Given the agglutinating morpheme complexity found within the Southern Bantu languages, it would stand to reason that morphological awareness and morpheme recognition would be important in reading for meaning.

Therefore, linguistic factors which need to be considered in understanding reading in the African languages include the type of orthography, phonological and morphological features (see also Trudell \& Schroeder 2007) and how these influence the grain size of word processing. Mindful of this, the main goal of this study was to investigate the effect of morphological and syllabic grain sizes on reading in conjunctive and disjunctive orthographies, respectively.

The following research questions are addressed in this article:

- What is the relative contribution of phonological awareness and morphological awareness in determining grain size literacy processing units in isiXhosa and Setswana, respectively?

- How do the types of grain size literacy processing units differ between L1 readers of a conjunctive orthography (isiXhosa) and L1 readers of a disjunctive orthography (Setswana)?

\section{Research methods and design Participants' schooling context}

Data were collected from 74 primary school children in Grades 3 and 4 at four different schools in the Eastern Cape and North West provinces. The four schools all served low socio-economic communities and were situated in semi-rural townships. The learners were either isiXhosa or Setswana first language speakers. ${ }^{5}$

To protect the anonymity of the schools and for ease of reference, each school will be referred to by a group code. The first school, X.EC, is an isiXhosa-medium school in a small coastal town in the Eastern Cape. The second school, E.EC, is a small English-medium school, also from a small town in the Eastern Cape. The majority of the children at this school are isiXhosa first language speakers. For the isiXhosa sample, the learners tested were in the final quarter of Grade 3 (Term 4). The third school, T.NW, is a Setswana-medium school in a small district in the North West Province. The fourth school, E.NW, is an English-medium school in the same district.

5.Although children in the sample were mother tongue speakers of African languages, some were at English-medium schools. This may have had an influence on their some were at English-ans and phonological awaren reading. However, this data sample was part of a larger dissertation which investigated the influence of language of part of a larger disserting (LoLT). Results ( $p>0$ in the ( $p>0.1$ for all variables) between the learners who attended English schools versus those who attended school in their L1. Language of learning and teaching did not impact on L1 reading strategies (see Probert 2015 for more on this). 
TABLE 1: Summary of the tasks used.

\begin{tabular}{|c|c|c|c|}
\hline $\begin{array}{l}\text { Phonological } \\
\text { awareness }\end{array}$ & $\begin{array}{l}\text { Morphological } \\
\text { awareness }\end{array}$ & $\begin{array}{l}\text { Open-ended } \\
\text { decomposition }\end{array}$ & $\begin{array}{l}\text { Oral reading } \\
\text { fluency task (ORF) }\end{array}$ \\
\hline $\begin{array}{l}\text { (Diemer 2015; } \\
\text { Probert 2016) }\end{array}$ & $\begin{array}{l}\text { (Rees 2016; } \\
\text { Probert 2016) }\end{array}$ & (Probert 2016) & $\begin{array}{l}\text { (Diemer 2015; } \\
\text { Probert 2016) }\end{array}$ \\
\hline 3 Tasks & 2 Tasks & 20 Sentences & $\begin{array}{l}\text { Timed task: } 1 \\
\text { minute }\end{array}$ \\
\hline Pseudo-words & Pseudo- and real words & Real sentences & - \\
\hline $\begin{array}{l}\text { Syllables and } \\
\text { phonemes }\end{array}$ & - & - & - \\
\hline $\begin{array}{l}\text { 1. Segmentation } \\
\text { 2. Isolation } \\
\text { 3. Deletion }\end{array}$ & $\begin{array}{l}\text { 1. Oral manipulation of } \\
\text { singular and plural } \\
\text { morphology: 'Wugs' } \\
\text { 2. Morpheme } \\
\text { identification }\end{array}$ & $\begin{array}{l}\text { Segmentation } \\
\text { of sentences } \\
\text { (e.g. syllables, } \\
\text { morphemes, } \\
\text { phonemes) }\end{array}$ & $\begin{array}{l}\text { Passage was read } \\
\text { aloud for } 1 \text { minute }\end{array}$ \\
\hline
\end{tabular}

The Setswana sample is composed of learners in the first quarter of their Grade 4 year (Term 1). ${ }^{6}$

\section{Measures, procedure and analysis}

To determine the grain size unit (Ziegler \& Goswami 2005; Ziegler et al. 2001) that learners use when reading conjunctive and disjunctive scripts, learners undertook four tasks: an open-ended decomposition task, a phonological awareness task, a morphological awareness task and an ORF task. There are currently no standardised measures of the metalinguistic skills for any of the Southern Bantu languages. These measures were therefore specifically developed for this study in both isiXhosa and Setswana and informed by linguistic principles unique to each of the languages.

All tasks were administered in the learners' first language (isiXhosa or Setswana) by a first language speaker of the language. The tasks took the form of word games. Learners were tested individually over a period of 2 days, with each participant spending a maximum of 20 minutes out of the classroom at a time. The ORF, phonological awareness task and parts of the morphological awareness task were recorded using a Dictaphone and Marantz recorder.

Table 1 provides a summary of the different tasks completed by the learners, the type of words used (real vs. pseudo) and the subtasks of each. Data coding for each task is discussed in more detail under each of the tasks.

\section{Phonological awareness}

The phonological awareness task consisted of three independent subtasks, each varying in linguistic and developmental difficulty. The three tasks included a segmenting, an isolation and a deletion task, which were codeveloped by Probert (2016) and Diemer (2015).

The subtasks were all administered orally as follows: for the segmenting task, participants were given a pre-selected word

6.Because of time constraints in working with four different schools, two of which were in different provinces, the data were collected at different times. However, every effort was made to ensure that data collection was done within a specific time frame in an effort to rule out as many variables as possible, which may have affected the outcome of the results. It must be acknowledged that this difference in data collection points serves as a limitation to the current study. However, although dat were gathered at different collection points from the isiXhosa (October) and Setswana (February) learners, a maximum of 3 months transpired between the two collection data points. The Setswana learners exposure to English was still minima during this early stage of the school year and was therefore not deemed a significan problem in its potential to skew the results. and asked to segment it into relative phonological units (i.e. the syllable or the phoneme), for example, /gefine/segmented according to syllables would be $/ g e-f_{I}-n e /$, and /tuze/ segmented according to phonemes would be $/ t-\tau-z-\varepsilon /$. The isolation task required participants to identify a specific phonological unit within a whole word, for example, 'what is the first sound in /jonele/?', the correct response would be /j/, and for 'what is the first syllable in /jonele/?', the correct response would be /jo/. The third task was a deletion task in which participants were asked to delete a specific phonological unit from a word, for a phoneme example, say '/setrre/ without $/ s /$ '. The correct response being /etrre/.

Pseudo-words were chosen for the stimuli and all pseudowords conformed to the orthographic and phonological properties of the language and were all pronounceable. They would therefore not have been seen by the participants prior to testing. Furthermore, shorter words were used as stimuli because the longer the word, the more difficult the task and the greater the cognitive load (Anthony et al. 2003). Therefore, two- and three-syllable pseudo-verbs were used, for example, tika, junala and tsilaba. Verbs were chosen, in particular, as the use of nouns requires noun class morphemes to be attached to the root, whereas for pseudo-verbs, there is no need for added morphemes and the manipulation can take place on the root alone.

Each of the phonological awareness tasks was coded separately on a three-point ordinal scale. A score of 2 was given for the correct answer, a score of 1 for a partially correct answer and a score of 0 for incorrect answers. There were equal items for each section of the assessment (10). Separate composition scores were computed for the set of syllable and phoneme tasks, respectively.

\section{Morphological awareness}

The morphological awareness task was originally developed by Rees (2016) for isiXhosa and adapted to Setswana (Probert 2016). The morphological awareness task consisted of two separate subtasks. They were (1) an oral manipulation of a singular and plural morphology task, more commonly known in the literature as the 'Wugs' test, and (2) a morpheme identification task. The oral manipulation of a singular and plural morphology task is an adaptation of the traditional test of inflectional awareness ('Wugs Test') (Berko 1958; Carlisle 2000) which requires learners to perform inflections on pseudo-words. This task aims to test children's inflectional morphological awareness, specifically their understanding of the noun classes in the language being tested. Participants were either asked the plural form after being given the singular form or asked for the singular form after being given the plural form. For example, the participant was presented with a pseudo-word containing the singular morpheme /le/ which is found in noun class 5 . To make this word plural, the participant would need to replace the noun class morpheme /le/ with the plural noun class / $\mathrm{ma} /$ from noun class 6 . This subtask was administered orally, with the aid of pictures indicating singular versus plural. 
For the 'Wugs' task, there were two criteria for each answer according to which the learners were assessed: (1) faithfulness to noun class (whether they used the correct noun class) and (2) singular to plural or plural to singular (whether they were able to go from singular to plural or plural to singular), for example, mora (sg) - mera ( $\mathrm{pl}$ ) / abazonko ( $\mathrm{pl}$ ) - umzonko (sg). Under each of these, the learners received a score of 1 if correctly identified and 0 if incorrect.

The morpheme identification task consisted of two parts: the first required the children to identify the part(s) of the word which mean negative. The second part asked them to identify past tense morphemes. It was chosen to look specifically at negation and past tense morphemes as these contain a range of allomorphs, for example, negation in the passive form, negation in the past tense, and so on. This was a written task and the participants were asked to highlight the morphemes which correspond to either negative or past tense in each of the respective languages. The children were given examples with different versions of the morphemes under investigation to avoid them replicating the example in every sentence. Morpheme identification is a decomposition task and tested both derivational and inflectional morphology. Real sentences were used, with morphemes at different syntactic positions in the sentences.

The identification task was scored on a three-point ordinal scale. The learners received a score of 2 if they identified at least one correct morpheme. A score of 1 was given when the learners highlighted the orthographic word where the morpheme rests, for example, the entire verb. Thus, for the sentence, 'Umama akaphekanga' the child highlighted 'phekanga', rather than ' $a k a$ ' and 'anga'. A score of 0 was given when the child failed to identify the correct morpheme. Using the same example, the child may have highlighted 'umama', or 'aka'.

A composite score was computed for morphological awareness based on the above set of tasks.

\section{Open-ended decomposition task}

The open-ended decomposition task is the first of its kind in South Africa. ${ }^{7}$ This task required the participants to segment sentences ${ }^{8}$ in any way they felt appropriate. Given the openended nature of this task, the participants were not provided with examples of how to break up the sentences according to phonemes, syllables or morphemes, as they may have based their responses on the last or on the best explained example. The sentences appeared in large print on an A4 paper which had been laminated and the participants used a whiteboard marker to indicate where they would break up the sentences (see Figure 1). A research assistant then replicated how the child had broken up the sentence on a separate list.

7.As this research formed part of the author's master's dissertation, there were time constraints placed on the collection of data resulting in the task not being able to be piloted.

8.Simple declarative sentences were used, which adhered to the consonant-vowe (CV) construction of these languages and followed the subject-verb-object (SVO) word order of the South Bantu Languages.

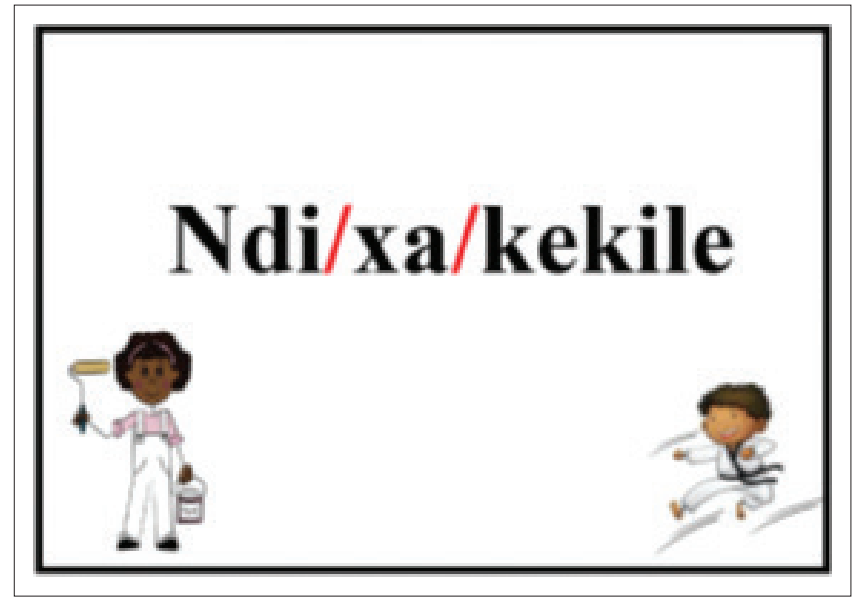

FIGURE 1: Example of a participant's response on decomposition task - IsiXhosa.

TABLE 2: Example of decomposition coding: 'Ideal' answer.

\begin{tabular}{|c|c|c|}
\hline English & I am busy & The children love each other \\
\hline IsiXhosa & Ndixakekile & Abantwana bayathandana \\
\hline $\begin{array}{l}\text { Sentence broken up according to } \\
\text { morphemes }\end{array}$ & Ndi-xakek-ile & Aba-ntwana ba-ya-thand-an-a \\
\hline No. of correct boundaries (score) & 2 & 5 \\
\hline $\begin{array}{l}\text { Sentence broken up according to } \\
\text { syllables }\end{array}$ & Ndi-xa-ke-ki-le & $\begin{array}{l}\text { A-ba-ntwa-na ba-ya-tha-nda- } \\
n a\end{array}$ \\
\hline No. of correct boundaries (score) & 4 & 7 \\
\hline $\begin{array}{l}\text { Overlap between syllable and } \\
\text { morpheme boundaries (score) }\end{array}$ & 1 & 3 \\
\hline
\end{tabular}

For the coding of the participants' responses, model answers were created according to whether the sentences were broken up into phonemes, syllables or morphemes (see Table 2). ${ }^{9}$ Each participant's answers were then judged against this model. It is important to indicate at this point that none of the participants broke up the sentences using a purely phonemic approach. ${ }^{10}$ The use of the syllable and morpheme in approaching sentence reading was therefore chosen as the particular point of focus. The correct, incorrect (incorrectly divided a syllable or morpheme) and total number of syllable or morpheme boundaries inserted were then counted. The scale used for the scoring of the decomposition task was ordinal, composed of intervals.

The participant PA2-011 in the example given in Table 3 below, scored one out of two for having correctly identified morpheme boundaries and four out of four for syllable boundaries for the first sentence.

The d-prime statistical method was run on the results of the open-ended decomposition task to test for relative grain size. $^{11}$ D-prime was originally developed within signal detection theory. It is a measure of sensitivity, computed on a basis of hit and false alarm rates (Kataoka \& Johnson 2007).

9.The model answers were checked by a first-language speaker of the language, with two linguistic lecturers from Rhodes University (one of whom had specialisation in morphology and the other in phonology), as well as with a lecturer from the African Languages Department at Rhodes University.

10.That is, breaking up the sentences by placing a 'line' between each grapheme.

11.The following formula was used when calculating d-prime in Excel, $=$ NORMSINV (HR) - NORMSINV (FA). The hit rate and false alarm rates were first transformed to their $z$-scores before calculations were made. $z$-Scores are the statistical measurement of a score's relationship to the mean in a group of scores (Howell 1999). 
TABLE 3: Example of decomposition coding: Real answer given by a participant.

\begin{tabular}{lll}
\hline PA2-011 & $\begin{array}{l}\text { Example sentence 1: } \\
\text { Ndixakekile }\end{array}$ & $\begin{array}{l}\text { Example sentence 2: } \\
\text { Abantwana bayathandana }\end{array}$ \\
\hline $\begin{array}{l}\text { Sentence as broken up } \\
\text { by participant }\end{array}$ & Ndi-xa-ke-ki-le & Aba-ntwa-na ba-ya-tha-nda-na \\
$\begin{array}{l}\text { Morphemes boundaries } \\
\text { correctly identified }\end{array}$ & 1 & 3 \\
$\begin{array}{l}\text { Syllables boundaries } \\
\text { correctly identified }\end{array}$ & 4 & 6 \\
$\begin{array}{l}\text { Overlap between syllable } \\
\text { and morpheme boundary }\end{array}$ & 1 & 3
\end{tabular}

Given the open-ended nature of this task, the d-prime statistic is the most appropriate analysis tool in that, according to the signal detection theory, nearly all decision-making takes place in the presence of some uncertainty (Kataoka \& Johnson 2007). A 'hit' was when a learner correctly identified a syllable or morpheme boundary where there was one present. A 'false alarm' was when a learner incorrectly identified a syllable or morpheme boundary where there was not one. D-prime was used as it uses a filter out effect, penalising guess work, as well as taking non-decisions and word breaks into account.

\section{Oral reading fluency}

Reading ability was measured using an ORF task. Participants were timed for 1 minute while reading the passage. This task was administered orally by first language speakers. Stories chosen were fictional and were at the appropriate grade level of the participants. ${ }^{12}$ The isiXhosa story had a total of 783 characters (110 words), and the Setswana story had a total of 1132 characters (285 words).

For the coding of the ORF task, the number of characters ${ }^{13}$ read accurately during the 1 minute interval was calculated. This was performed by subtracting the errors from the total number of characters read in a minute to get a score of correct characters read per minute (ccrpm).

\section{Ethical considerations}

Approval to conduct this research was obtained from the following gatekeepers: Rhodes University Ethical Standards Committee (ethical clearance tracking number: RUHSD-14-02-0001), the Eastern Cape and North West Departments of Basic Education and school principals. In addition, parental consent and learner assent were sought and gained prior to testing. Each participant was assigned a code in order to ensure anonymity. All schools and participants were asked to volunteer to participate in this study.

\section{Data analysis}

Univariate statistics were conducted on the tasks undertaken by the learners. The probability plot correlation coefficient (PPCC) for normality was used to determine the normal distributions between the two language samples. Scores were

12.The isixhosa passage was obtained from Nali'Bali. The Setswana passage was obtained from the Resource Centre of the University's Education Department.

13.The number of characters read per minute was calculated rather than the words read per minute, as the concept of what a word is differs from isiXhosa to Setswana. Coding it as words read per minute would result in an infelicitous comparison. Using characters makes it easier to compare across the two orthographies. normally distributed for each sample. ${ }^{14} t$-Tests (independent samples) were then used to test for statistical differences between the two groups, that is, isiXhosa and Setswana. For the decomposition task, the d-prime statistical method was run on the results to test for grain size. Pearson's correlation matrix was used to investigate the relationship between the metalinguistic skills. Finally, a multiple linear regression analysis was conducted to determine the relative contribution of phoneme awareness, syllable awareness and morphological awareness in predicting ORF scores. A reliability analysis (Cronbach's alpha) was also performed for each set of tasks (excluding $\mathrm{ORF}^{15}$ ).

\section{Results}

\section{Research Question 1: What is the relative contribution of Phonological Awareness and Morphological Awareness in determining grain size literacy processing units in isiXhosa and Setswana?}

Table 4 provides the descriptive statistics for isiXhosa and Setswana. This includes the mean percentages, standard deviations, $t$-score and $p$-value and reliability measure (alpha) for the metalinguistic tasks for isiXhosa and Setswana. As can be seen, the alpha indices for syllable awareness and phoneme awareness were high, but not so for morphological awareness.

Setswana learners did significantly better with phonological awareness (both syllable and phoneme awareness) than the isiXhosa learners. This is shown through the higher mean scores for these tasks for the Setswana group. Using a two sample $t$-test, it was found that the difference for syllable awareness and phoneme awareness between the isiXhosa learners and the Setswana learners was statistically significant (syllable awareness $t(72)=4.56 p<0.001$; phoneme awareness $t(72)=2.59, p<0.05)$. Furthermore, the results show that performance on the syllable awareness task is higher than that for phoneme awareness for both isiXhosa (72.4 in comparison to 44.39) and Setswana learners (87.53 in comparison to 56.06). This difference was statistically significant for both groups (isiXhosa: $t(39)=7.25, p<0.001$; Setswana: $t(31), p<0.001)$.

For morphological awareness, the isiXhosa learners scored higher than the Setswana learners ( $M=57.36$ vs. $M=43.28)$. The difference in scores of the morphological awareness task was also found to be significant $(t[72]=-4.83, p<0.001)$. However, the results must be interpreted cautiously, as the reliability index was low (0.44).

To determine which of these variables best predicted reading fluency, a multiple regression (see Table 5) was conducted using the standard method, with ORF (ccrpm) as the

14. Syllable awareness $=0.98$ (isiXhosa and Setswana), phoneme awareness $=0.98$ (isiXhosa), 0.97 (Setswana), morphological awareness $=0.99$ (isiXhosa), 0.98 (Setswana).

15.Alpha cannot be used on speeded tests. 
TABLE 4: Descriptive statistics: Syllable awareness, phoneme awareness, morphological awareness and oral reading fluency.

\begin{tabular}{|c|c|c|c|c|c|c|c|}
\hline \multirow[t]{2}{*}{ Variable } & \multicolumn{2}{|c|}{ isiXhosa $(N=41)$} & \multicolumn{2}{|c|}{ Setswana $(N=33)$} & \multicolumn{2}{|c|}{ Statistic } & \multirow[t]{2}{*}{ Reliability $(\alpha)$} \\
\hline & $M$ & SD & $M$ & SD & $T$ & $p$ & \\
\hline Syllable awareness total & 72.4 & 16.3 & 87.53 & 10.98 & 4.56 & $<0.001 * *$ & 0.85 \\
\hline Phoneme awareness total & 44.39 & 18.99 & 56.06 & 19.63 & 2.59 & $<0.05^{*}$ & 0.88 \\
\hline Morphological awareness total & 57.36 & 15.02 & 43.28 & 8.2 & -4.83 & $<0.001 * *$ & 0.44 \\
\hline ORF (ccrpm) (wcpm) & $128(12)$ & 100.74 & 100 (29) & 62.22 & 1.35 & 0.18 & - \\
\hline
\end{tabular}

$M$, mean; SD, standard deviation; $\alpha$, Cronbach's alpha; ORF, oral reading fluency; ccrpm, correct characters read per minute; wcpm, words correct per minute.

*, Significant at the 0.05 level; **, Significant at the 0.001 level.

TABLE 5: Results of multiple regression analysis with oral reading fluency as a dependent variable.

\begin{tabular}{|c|c|c|c|c|c|c|c|c|c|c|}
\hline \multirow[t]{2}{*}{ Variable } & \multirow[t]{2}{*}{$B$} & \multicolumn{4}{|c|}{ IsiXhosa $(n=41) \dagger$} & \multirow[t]{2}{*}{$B$} & \multicolumn{4}{|c|}{ Setswana $(n=33)$} \\
\hline & & Std. error & $\beta$ & $t$-value & $p$ & & Std. error & $\beta$ & $t$-value & $p$ \\
\hline (intercept) & -37.319 & 85.620 & & -0.436 & 0.665 & -74.504 & 77.49 & & -0.961 & 0.3443 \\
\hline Morphological awareness & -0.900 & 1.036 & -0.134 & -0.868 & 0.391 & -2.083 & 1.307 & -0.275 & -1.594 & 0.122 \\
\hline Syllable awareness & 2.518 & 0.939 & 0.407 & 2.682 & $0.011^{*}$ & 2.451 & 1.100 & 0.432 & 2.228 & $0.034 *$ \\
\hline Phoneme awareness & 0.782 & 0.805 & 0.147 & 0.972 & 0.37 & 0.912 & 0.549 & 0.288 & 1.662 & 0.107 \\
\hline
\end{tabular}

$B$, unstandardised coefficient; $\beta$, standardised coefficient/beta; std. standard.

*, Significant at $p<0.05$.

$\dagger$, Residual standard error: 94.87 on 37 degrees of freedom (DF); multiple $R$-squared: 0.1795 ; adjusted $R$-squared: $0.113 ; F$-statistic: 2.698 on 3 and 37 DF; $p$-value: 0.05974 .

$\$$, Residual standard error: 53.02 on 29 degrees of freedom; multiple $R$-squared: 0.3418 ; adjusted $R$-squared: $0.2738 ; F$-statistic: 5.021 on 3 and 29 DF; $p$-value: 0.006335 .

TABLE 6: $R$-values of Pearson correlations between morphological awareness, syllable awareness, phoneme awareness and oral reading fluency.

\begin{tabular}{|c|c|c|c|c|c|c|c|c|}
\hline \multirow[t]{2}{*}{ Variable } & \multicolumn{4}{|c|}{ IsiXhosa $(N=41)$} & \multicolumn{4}{|c|}{ Setswana $(n=33)$} \\
\hline & $\begin{array}{c}\text { Morphological } \\
\text { awareness }\end{array}$ & Syllable awareness & $\begin{array}{c}\text { Phoneme } \\
\text { awareness }\end{array}$ & ORF & $\begin{array}{c}\text { Morphological } \\
\text { awareness }\end{array}$ & $\begin{array}{c}\text { Syllable } \\
\text { awareness }\end{array}$ & $\begin{array}{c}\text { Phoneme } \\
\text { awareness }\end{array}$ & ORF \\
\hline Morphological awareness & - & 0.196 & 0.192 & -0.026 & - & $0.456^{*}$ & 0.067 & -0.058 \\
\hline Syllable awareness & - & - & 0.024 & $0.384 *$ & - & - & $0.465^{*}$ & $0.441 *$ \\
\hline Phoneme awareness & - & - & - & 0.131 & - & - & - & $0.470 *$ \\
\hline ORF & - & - & - & & - & - & - & \\
\hline
\end{tabular}

ORF, oral reading fluency.

*, Correlation is significant at the 0.01 level.

TABLE 7: Decomposition task (d-prime) results for isiXhosa and Setswana learners.

\begin{tabular}{|c|c|c|c|c|c|c|c|c|c|}
\hline \multirow[t]{2}{*}{ Variable } & \multicolumn{4}{|c|}{ IsiXhosa } & \multicolumn{4}{|c|}{ Setswana } & \multirow[t]{2}{*}{ Reliability $(\alpha)$} \\
\hline & Average d-prime & SD & HR & FA & Average d-prime & SD & HR & FA & \\
\hline \multicolumn{10}{|l|}{ Grain size } \\
\hline Syllables & 1.2 & 1.07 & $71 \%$ & $29 \%$ & 1.49 & 0.83 & $75 \%$ & $25 \%$ & 0.38 \\
\hline Morphemes & 0.58 & 0.58 & $60 \%$ & $40 \%$ & -0.21 & 0.28 & $45 \%$ & $55 \%$ & 0.61 \\
\hline
\end{tabular}

$\mathrm{HR}$, hit rate; FA, false alarm rate; $\alpha$, Cronbach's alpha; $\mathrm{Cl}$, confidence interval; SD, standard deviation.

dependent variable and phoneme awareness, syllable awareness and morphological awareness as independent variables. The $r$-values of the Pearson correlations are given in Table 6. Significance is indicated with an asterisk.

Results from the regression analysis showed that only syllable awareness significantly predicted ORF for both isiXhosa $(p=0.011)$ and Setswana $(p=0.034)$, and accounted for $14 \%\left(R^{2}=0.148, \mathrm{SE}=0.148\right)$ and $19 \%\left(R^{2}=0.194, \mathrm{SE}=0.161\right)$ of the variance, respectively. Neither morphological awareness (Xhosa: $p=0.39$; Setswana: $p=0.12$ ) nor phoneme awareness (Xhosa: $p=0.37$; Setswana: $p=0.107$ ) was found to significantly predict ORF.

\section{Research Question 2: How do types of grain size literacy processing units differ in isiXhosa and Setswana readers?}

This section explores the preferences in grain size while reading connected linguistic units. This is based on the results of the decomposition task using the d-prime statistical method. Particular attention was paid to the use of syllables and morphemes in breaking up sentences. ${ }^{16}$ Table 7 provides a summary of the results on the decomposition task for isiXhosa and Setswana learners.

The Setswana learners $(M=1.49, \mathrm{SD}=0.826, H R=75 \%)$ were more inclined to break up sentences into syllables than the isiXhosa group $(M=1.20, \mathrm{SD}=1.07, H R=71 \%)$. This is indicated by the mean scores and hit rates. The difference found was, however, not statistically significant $(t[72]=1.64$, $p=0.11)$. This is consistent with the results in Table 4 which shows that readers for both languages scored very well on syllable awareness measures, as well as with the regression model which shows that only syllable awareness was predictive of ORF in both isiXhosa and Setswana.

For morphemes, the isiXhosa learners $(M=0.58, \mathrm{SD}=0.57$, $\mathrm{HR}=60 \%$ ) tended to the morpheme more than the Setswana learners $(M=-0.23, \mathrm{SD}=0.28, H R=45 \%)$. This difference was statistically significant $(t[72]=7.22, p<0.001)$. In particular, the Setswana readers had a false alarm rate of $55 \%$ which,

16.The reason for this is that, as mentioned earlier, none of the learners broke up words according to the phoneme level and/or whole word level. 
if statistically significant, is worse than chance. For the open-ended task, learners were not primed to parse in any particular way. The fact that some learners chose to parse morphologically is important. It suggests that (1) these readers include a morphological component in their reading strategies but (2) it is not helpful to them. This suggests that a morphological parsing strategy is not helpful to Setswana readers (even for those readers who chose to parse in this way). In contrast, isiXhosa readers achieved better-thanchance success at identifying morpheme boundaries which shows that morphological parsing is a useful part of their text-decoding strategy. As Setswana is written largely disjunctively, the blank space often separates out at least some morphemes (especially in the verbal complex - but not for noun class prefixes amongst others). Thus, a morphological parsing strategy would be redundant at least part of the time. In contrast, the conjunctive style of isiXhosa presents readers with longer, multimorphemic words. Presented with this type of textual puzzle, a morphological parsing strategy can significantly assist in breaking up long words into smaller units. Consequently, it is expected that isiXhosa learners would include a morphological parsing as part of their reading strategy. It therefore appears that conjunctivism sets up the need for heightened morphological awareness.

\section{Discussion}

The general reading ability of the learners was extremely low. According to Spaull et al. (2017), the thresholds for reading in Grade 3 in Northern Sotho (similar to Setswana) are 39-48 words correct per minute (wcpm) and 20-32 in isiZulu (similar to isiXhosa). The learners in this study were reading at an average of $29 \mathrm{wcpm}$ in Setswana and $12 \mathrm{wcpm}$ in isiXhosa, which is substantially below the threshold. The findings showed the dominant use of the syllable when reading connected-text very slowly, which was supplemented by the use of the morpheme in isiXhosa. The syllable was also found to be the only significant metalinguistic skill which correlated to and was predictive of ORF scores.

\section{Effect of conjunctivism and disjunctivism on grain size reading processing units}

The decomposition task showed that learners use multiple grain sizes. This was particularly true for the isiXhosa learners. Using multiple grains in reading can be situated in the flexible-unit-size hypothesis (Brown \& Deavers 1999; Ziegler \& Goswami 2005), which states that English readers use a mixture of small and large grain size units in decoding strategies (Pae 2014; Ziegler \& Goswami 2005). This hypothesis, however, has been limited to English word identification. The findings show that it can be extended and applied beyond English. In particular, even readers of a consistent orthography make use of more than one grain size. In the Southern Bantu languages, there is often an overlap in syllables and morphemes in the prefix domain. It is thus logical for these learners to develop syllable- and morphemesized units in parallel.
For phonological awareness, both isiXhosa and Setswana learners scored higher on syllable awareness than phoneme awareness. This finding is consistent with that of Tolchinsky and Teberosky (2017) and that of Diemer et al. (2015). She reported similar results and showed that isiXhosa learners show greater awareness of the syllable as a phonological unit than the phoneme. This finding can also be situated within the hierarchical model of word recognition (Anthony \& Lonigan 2004; Scheule \& Boudreau 2008; Ziegler \& Goswami 2005), which confirms that an awareness of larger units (e.g. the syllable) precedes awareness of smaller units (e.g. the phoneme) (Ziegler \& Goswami 2005). This is attributable to phonological development on the part of the learner, but also because of the nature of the Southern Bantu languages' phonological structure which tends to favour the syllable because of its consistent CV structure, with few consonant clusters and codas (Diemer 2015). Furthermore, the scores of the decomposition task suggest that the syllable is a primary grain size for both isiXhosa and Setswana learners. Syllable awareness was also found to be predictive of ORF in both isiXhosa and Setswana. This finding is particularly interesting in that the use of characters per minute is novel and shows that syllable awareness is important. However, when orthographic words per minute are used, the literature has shown that only phoneme awareness is important (Cunningham 1989; Diemer 2015; Godoy et al. 2017). It is therefore dependent on what is used to calculate what the ORF is. Nevertheless, these findings suggest that the use of the syllable could be a productive reading strategy for learners to use when reading connected-text in these languages. In contrast, it has generally been found that although English-speaking children have higher syllable awareness than phoneme awareness when beginning to read, it does not necessarily make it productive for them to use syllables as a grain for word recognition. This is probably because of the diversity of syllable types in English. However, the question remains whether this is true for the Southern Bantu languages in which the structure of syllables is simpler. Given this, the syllable could conceivably be more useful in word reading in these languages. Because the African languages are strongly syllabic, children find it relatively easy to identify syllables in their words.

Although the syllable was found to be the dominant grain size unit used in connected-text reading in both languages, the isiXhosa readers showed a greater sensitivity towards the use of the morpheme. This could be attributed to the conjunctive nature of isiXhosa. IsiXhosa learners need to know where the morphological segments are when breaking up sentences. This is because words are made up of a combination of prefixes and suffixes that are added to noun and verbal elements, so the ability to use morphological knowledge while reading is very important. They therefore pay closer attention to the morpheme which holds meaning. In contrast, the Setswana orthography tends to break up the linguistic word into syllables. However, some morphemes in Setswana are syllabic. The syllable and morpheme are often confounded. For this reason, when referring to grain 
size used by these learners, it may appear that they use the syllable as the dominant grain, but the morpheme cannot be excluded.

Studies across many different languages, such as Dutch (e.g. Libben 1994), English (e.g. Bradley 1980; MarlsonWilson et al. 1994; Taft \& Forster 1976), Italian (e.g. Caramazza, Laudanna \& Romani 1988) and Serbo-Croatian (e.g. Feldman \& Andjelkovic 1992), support the view that morpheme recognition and analysis contribute to word decoding. This is because reading strategies which involve morpheme recognition provide to some extent a direct mapping onto the lexicon of spoken words (Elbro \& Arnbak 1996). For example, the mental lexicon may be organised in terms of stems and their endings rather than as wholes (Marlson-Wilson et al. 1994). Because of the nature of the conjunctive orthography, words in isiXhosa are particularly long; therefore, it follows that learners break up words into meaningful sections rather than attempting whole-word recognition. Using a grapheme-to-phoneme approach to decoding may also prove a cognitively heavy task, especially for long words which impose a burden on working memory. According to Carlisle and Stone (2005), readers benefit significantly from exposure to variant spellings of particular morphemes, and from practice in finding those morphemes within a string of affixes attached to the base word. Expectation of a certain morpheme in a particular slot in the verbal or nominal phrase, for instance, may be especially valuable for readers of Southern Bantu languages. This is because an awareness of the morphological structure can assist with complex word reading in languages which are morphologically rich in character and are thus automatically more complex (Acha, Laka \& Perea 2010; Saiegh-Haddad \& Geva 2007).

Furthermore, according to a study by Burani et al. (2008), who studied Italian readers, the morpheme is useful as a grain size for readers who have not yet fully mastered wholeword processing. This is particularly useful where 'whole words' are (1) long and (2) characterised by high levels of orthographic neighbourhood effects. Morphemic processing thus aids grapheme-to-phoneme decoding. Using the morpheme as a grain size also provides a lexical reading unit larger than the grapheme, but smaller than the whole word, which reduces the limitations owed to the analytical process of reading. This explanation by Burani et al. (2008) is important in explaining why the morpheme acts as a grain size in isiXhosa more than it does in Setswana. Setswana readers can rely on whole-word (lexical) parsing because of the disjunctive orthography which splits up the linguistic word. However, because of the conjunctive script, readers of isiXhosa cannot rely on whole-word (lexical) parsing because of the length of the words. They would need to use another grain size in decoding. Although the regression analysis indicated that morphological awareness was not a significant predictor of ORF in isiXhosa readers $(p=0.39)$, it may be that these learners were still reading too slowly to unglue themselves from the syllable.
Despite this, the isiXhosa learners demonstrated sensitivity towards the use of the morpheme in connected-text reading. The use of the morpheme as a grain size may therefore become more important as learners become more fluent. A longitudinal study would be necessary to determine whether morphological awareness plays a greater role for these learners at the higher grades. However, it must be acknowledged that the reliability index for the morphology test is low. There is therefore an urgent need for further research to be conducted on improving morphology assessments. Furthermore, the learners in this study were reading extremely slowly, and there is no information on how they were taught to read. More research on the contribution of syllable, phoneme and morphological factors needs to be undertaken, at different grades, and include learners with stronger reading skills.

Nevertheless, it has been shown that different languages require different metalinguistic skills when reading. These, along with the grain size unit which learners use as literacy processing units, are conditioned by the orthography in which the learner reads.

\section{Conclusion}

This article explored the effect that disjunctivism and conjunctivism of an orthography have on the differential use of grain sizes in reading strategies in isiXhosa and Setswana.

The findings showed that:

- Setswana learners performed better on phonological awareness tasks than the isiXhosa learners.

- Both Setswana and isiXhosa learners did better on syllable awareness tasks than they did on phoneme awareness tasks.

- The isiXhosa learners did better on morphological awareness tasks than the Setswana learners.

- On the decomposition task, Setswana learners scored higher for syllables, with isiXhosa learners scoring higher for morphemes.

- Syllable awareness was a significant predictor of ORF in both isiXhosa and Setswana learners.

These findings support previous research regarding word recognition models and developmental patterns of reading. Studies on grain sizes in different orthographies have focused on a comparison of orthographic depth, comparing transparent to opaque orthographies. This study examined two languages with similar orthographic depth, but different writing systems. Morphological awareness appears to play a greater role for learners of a conjunctive orthography than for learners of a disjunctive orthography, with isiXhosa learners exhibiting higher levels of morphological awareness than the Setswana learners. Furthermore, the isiXhosa learners used the morpheme as a secondary grain in decoding.

Learners approached connected-text reading based upon the writing systems and language-specific structures of the 
language. An understanding of reading in the Southern Bantu languages should take into cognisance the linguistic processing units which underpin reading strategies, as well as how the orthography informs metalinguistic awareness skills. This should, in turn, inform teaching strategies and curriculum statements. Using a one-size-fits-all model further entrenches inequalities in literacy by making literacy inaccessible for the learners, who are already playing catch-up. An alignment between reading instruction with orthography will work towards ensuring that learners are exposed to reading strategies and instructions which are best suited to the language in which they are learning to read. It is evident that learners exhibit a strong awareness and sensitivity towards the syllable. Thus, the use of the syllable in connected-text reading becomes a simple and useful technique. However, the use of the phoneme remains necessary in achieving reading success (Cunningham 1989; Diemer 2015; Godoy et al. 2017). The use of the syllable in early word reading acts as a bridge to fluent decoding of words in reading. Furthermore, because of the nature of the rich morphological structures of the African languages, an approach that places greater emphasis on heightening morphological awareness is necessary. This is particularly relevant for isiXhosa L1 readers in the Foundation Phase where the use of morphemes as a word reading strategy in connected-text reading would prove beneficial.

This article contributes to a growing body of rigorous, transparent research which is needed to help build up knowledge and deepen understanding in the domain on literacy in the African languages. The focus of this article was on first language reading. Research is still needed in second-language reading, which would introduce the question of transfer of grain size. Furthermore, research with a bigger sample size is needed for further amplification of these findings.

\section{Acknowledgements}

The author wishes to extend her sincere thanks to the schools, teachers and learners for their generous participation in the study. She would also like to thank Prof. Mark de Vos for his invaluable supervision of this research.

\section{Competing interests}

The author declares that she has no financial or personal relationships that may have inappropriately influenced her in writing this article.

\section{Funding information}

Data collection for this research was funded by the Sandisa Imbewu Project. This research was conducted under the supervision of Prof. Mark de Vos from the Rhodes University's Department of English Language and Linguistics.

\section{References}

Aaron, P.G. Joshi, R.M., Ayotollah, M., Ellsberry, A., Henderson, J. \& Lindsey, K., 1999 'Decoding and sight-word naming: Are they independent components of word recognition skill?' Reading and Writing: An Interdisciplinary Journal 11, 89-127. https://doi.org/10.1023/A:1008088618970
Acha, J., Laka, I. \& Perea, M., 2010, 'Reading development in agglutinative languages: Evidence from beginning, intermediate and adult Basque readers', Journal of Experimental Child Psychology 105, 359-375. https://doi.org/10.1016/j.jecp. 2009.10.008

Anthony, J.L. \& Francis, D.J., 2005, 'Development of phonological awareness', Current Directions on Psychological Science 14(5), 255-259. https://doi.org/10.1111/ j.0963-7214.2005.00376.x

Anthony, J.L. \& Lonigan, C.J., 2004, 'The nature of phonological sensitivity: Converging evidence from four studies of Preschool and Early-grade School Children', Journa of Educational Psychology 96, 43-55. https://doi.org/10.1037/0022-0663.96.1.43

Anthony, J.L., Lonigan, C.J., Driscoll, K., Phillips, B.M. \& Burgess, S.R., 2003 'Phonological sensitivity: A quasi-parallel progression of word structure units and cognitive operations', Reading Research Quarterly 38, 470-487. https://doi. org/10.1598/RRQ.38.4.3

Berko, J., 1958, 'The child's learning of English morphology', Word 14, 150-177. https://doi.org/10.1080/00437956.1958.11659661

Bradley, D., 1980, 'Lexical representation of derivational relation', in M. Aronoff \& M.L. Kean (eds.), Juncture, pp. 37-55, Anma Libri, Saratoga, CA

Bradley, L. \& Bryant, P.E., 1985, Rhyme and reason in reading and spelling, University of Michigan Press, Ann Arbor, Ml.

Brown, G.D.A. \& Deavers, R.P., 1999, 'Units of analysis in non-word reading: Evidence from children and adults', Journal of Experimental Child Psychology 73, 208-242.

Burani, C., Marcolini, S., De Luca, M. \& Zoccolotti, P., 2008, 'Morpheme-based reading aloud: Evidence from dyslexic and skilled Italian readers', Cognition 108, 243-264. https://doi.org/10.1016/j.cognition.2007.12.010

Caramazza, A., Laudanna, A. \& Romani, C., 1988, 'Lexical access and inflectional morphology', Cognition 28, 297-332. https://doi.org/10.1016/0010-0277(88) 90017-0

Carlisle, J.F., 2000, 'Awareness of the structure and meaning of morphologically complex words: Impact on Reading', Reading and Writing: An Interdisciplinary Journal 12, 169-190. https://doi.org/10.1023/A:1008131926604

Carlisle, J.F., 2003, 'Morphology matters in learning to read: A commentary', Reading Psychology 24, 291-332. https://doi.org/10.1080/02702710390227369

Carlisle, J.F. \& Stone, S.A., 2005, 'Exploring the role of morphemes in word reading', Reading Research Quarterly 40(4), 428-447. https://doi.org/10.1598/RRQ.40.4.3

Carraeiras, M. \& Perea, M., 1998, 'Effects of syllable frequency and syllable neighborhood frequency in visual word recognition', Journal of Experimental Psychology: Human Perception and Performance 24, 134-144. https://doi. org/10.1037/0096-1523.24.1.134

Casalis, S. \& Louis-Alexandre, M.F.L., 2000, 'Morphological analysis, phonologica analysis and learning to read French: A longitudinal study', Reading and Writing 12, 303-335. https://doi.org/10.1023/A:1008177205648

Castles, A. \& Coltheart, M., 2004, 'Is there a causal link from phonological awareness to success in learning to read?', Cognition 91, 77-111. https://doi.org/10.1016/ S0010-0277(03)00164-1

Chard, D.J. \& Dickson, S.V., 1999, 'Phonological awareness: Instructional and assessment guidelines', Intervention in School and Clinic 34, 5, viewed from www.Idonline.org/ Idindepth/reading/chard_phono_awareness.html

Cook, V. \& Bassetti, B., 2005, 'An introduction to researching second language writing systems', in V.J. Cook \& B. Bassetti (eds.), Second Language writing systems, pp. 1-67, Multilingual Matters, Clevedon.

Cunningham, A.E., 1989, 'Phonemic awareness: The development of early reading competency', Reading Research Quarterly 24, 471-472.

Diemer, M.N., 2015, 'The contributions of phonological awareness and naming speed to the reading fluency, accuracy, comprehension and spelling of Grade 3 isiXhosa readers', Unpublished MA dissertation, Grahamstown, Rhodes University.

Diemer, M., Van der Merwe, K. \& De Vos, M., 2015, 'The development of phonological awareness literacy measures for IsiXhosa', Southern African Linguistics and Applied Language Studies 33(3), 325-341. https://doi.org/10.2989/16073614.20 15.1108769

Durgunoğlu, A.Y. \& Öney, B., 1999, 'A cross-linguistic comparison of phonological awareness and word recognition', Reading and Writing: An Interdisciplinary Journal 11, 281-99. https://doi.org/10.1023/A:1008093232622

Elbro, C. \& Arnbak, E., 1996, 'The role of morpheme recognition and morphological awareness in dyslexia', Annals of Dyslexia 46, 209-240. https://doi.org/10.1007/ BF02648177

Feldman, L.B. \& Andjelkovic, D., 1992, 'Morphological analysis in word recognition', in L. Katz \& R. Frost (eds.), Orthography, phonology, morphology and meaning: An overview, pp. 343-360, Elsevier, Amsterdam.

Godoy, D.M.A., Pinheiro, A.M.V. \& Citoler, S.D., 2017, 'Initial literacy: Influence of phonemic awareness and teaching method', Psicologia: Teoria e Prática 19(3), 226-241. https://doi.org/10.5935/1980-6906/psicologia.v19n3p226-241

Goswami, U., 2002, 'Phonology, reading development, and dyslexia: A cross-linguistic perspective', Annals of Dyslexia 52, 141-162. https://doi.org/10.1007/s11881002-0010-0

Heugh, K., 2000, The case against bilingual and multilingual education in South Africa, PRAESA Occasional Papers No. 6., University of Cape Town, Cape Town.

Howell, D.C., 1999, Fundamental statistics for the behavioural sciences, 4th edn., Brooks/Cole Publishing Company, Pacific Grove, CA

Howie, S., Combrinck, C., Roux, K., Tshele, M., Mokoena, G. \& McLeod Palane, N., 2017, PIRLS 2016 progress in international reading literacy study 2016: South African children's reading literacy achievement, Centre for Evaluation and Assessment, Pretoria. 
Howie, S., Van Staden, S., Tshele, M., Dowse, C. \& Zimmerman, L., 2012, South African children's reading literacy achievement: Executive Summary 2011, CEA, University of Pretoria, Pretoria.

Howie, S., Venter, E., Van Staden, S., Zimmerman, L., Long, C., Scherman, V. et al., 2008, Progress in International Reading Literacy Study 2006, Summary report. South African children's reading literacy achievement, Centre for Evaluation and Assessment, University of Pretoria, Pretoria.

Invernizzi, M. \& Hayes, L., 2010, 'Developmental patterns of reading proficiency and reading difficulties', in R. Allington \& A. McGill-Franzen (eds.), Handbook of reading disabilities research, International Reading Association, Newark, pp. 196-207.

Jiménez, J.E. \& Ortiz, M.R., 2000, 'Metalinguistic awareness and reading acquisition in the Spanish Language', Spanish Journal of Psychology 3, 37-46. https://dol. org $/ 10.1017 /$ S1138741600005527

Kataoka, R. \& Johnson, K., 2007, Frequency effects in cross-linguistic stop place perception: A case of $/ t /-/ k /$ in Japanese and English, University of California at Berkeley Phonology Lab Annual Report, University of California, Berkeley, CA pp. 273-301.

Katz, L. \& Frost, R., 1992a, 'Orthography, phonology, morphology, and meaning: An overview', in R. Frost \& L. Katz (eds.), Orthography, phonology, morphology, and meaning, pp. 1-8, Elsevier North Holland Press, Amsterdam.

Katz, L. \& Frost, L., 1992b, 'Reading in different orthographies: The orthographic depth hypothesis', in R. Frost \& L. Katz (eds.), Orthography, phonology morphology, and meaning, pp. 67-84, Elsevier, Amsterdam.

Kirby, J.R., Deacon, S.H., Bowers, P.N., Izenberg, L. Wade-Woolley, L. \& Parrila, R. 2012, 'Children's morphological awareness and reading ability', Reading and Writing 25, 389-410. https://doi.org/10.1007/s11145-010-9276-5

Koda, K., 2007, 'Reading and language learning: Cross-linguistic constraints on second language reading development', Language learning 57(suppl.1), 1-44. https:// doi.org/10.1111/0023-8333.101997010-i1

Land, S.J., 2015, 'Reading isiZulu: Reading processes in an agglutinative language with a transparent orthography', PhD dissertation, pp. 1-195.

Libben, G., 1994, 'How is morphological decomposition achieved?', Language and Cognitive Processes 9(3), 369-391. https://doi.org/10.1080/0169096940840212

Louwrens, L. \& Poulos, G., 2006, 'The status of the word in selected conventional writing systems - The case of disjunctive writing', Southern African Linguistics and Applied Language Studies 24, 389-401. https://doi.org/10.2989/16073610 609486427

Marlson-Wilson, W., Komisarjevsky, L., Waksler, R. \& Older, L., 1994, 'Morphology and meaning in the English Mental lexicon', Psychological Review 101(1), 3-33. https://doi.org/10.1037/0033-295X.101.1.3

Mattingly, I.G. 1992, 'Linguistic awareness and orthographic form', in R. Frost \& L. Katz (eds.), Orthography, phonology, morphology, and meaning, pp. 11-26, Elsevier Science Publishers, B.V, Amsterdam.

McBride-Chang, C., Wagner, R.K., Muse, A., Chow, B.W.Y. \& Shu, H., 2005, 'The role of morphological awareness in children's vocabulary acquisition in English', Applied Psycholinguistics 26(3), 415-435. https://doi.org/10.1017/S014271640505023X

Nurse, D. \& Philippson, G., 2003, Introduction: The Bantu Languages, Routledge, London.

Pae, H.K., 2014, 'Processing of alternated and inverse fonts in word recognition by native and non-native speakers of English', Athens Journal of Philosophy 1(4), 233-244.

Perfetti, C.A., 1994, 'Psycholinguistics and reading ability', in M.A. Gernsbacher (ed.), Handbook of psycholinguistics, pp. 849-894, Academic Press, San Diego, CA.

Pretorius, E. \& Mokhwesana, M., 2009, 'Putting reading in Northern Sotho on track in the early years: Changing resources, expectations and practices in a High Poverty the early years: Changing resources, expectations and practices in a High Poverty
School', South African Journal of African Languages 1, 54-73. https://doi.org/10. School', South African Journal of Af

Pretorius, E.J. \& Spaull, N., 2016, 'Exploring relationships between oral reading fluency and reading comprehension amongst English second language readers in South Africa', International Journal: Reading and Writing 29(7), pp. 1449-1471. houth Africa', International Journal: Reading

Probert, T., 2016, 'A comparative study of syllables and morphemes as literacy processing units in word recognition: IsiXhosa and Setswana', Unpublished MA dissertation, Rhodes University, Grahamstown.

Probert, T. \& De Vos, M., 2016, 'Word recognition strategies amongst IsiXhosa/English Bilingual Learners: The interaction of orthography and language of learning and teaching', Reading \& Writing 7(1), a84. https://doi.org/10.4102/rw.v7i1.84
Rees, S., 2016, 'Morphological awareness in readers of isiXhosa', Master's thesis, English Language and Linguistics, Rhodes University, Grahamstown, South Africa.

Saiegh-Haddad, R. \& Geva, E., 2007, 'Morphological awareness, phonological awareness and reading in English-Arabic bilingual children', Reading and Writing: An Interdisciplinary Journal 21(5), 481-504.

Scheule, C. \& Boudreau, D., 2008, 'Phonological awareness intervention: Beyond the basics', Language, Speech \& Hearing Services in Schools 39(1), 3-20. https://doi. org/10.1044/0161-1461(2008/002)

Scholfield, P. \& Chwo, G.S., 2005, 'Are the L1 and L2 word reading processes affected more by writing system or instruction?', in V. Cook \& B. Bassetti (eds.), Second language writing systems, pp. 215-237, Multilingual Matters, Clevedon.

Shankweiler, D. \& Fowler, A.E., 2004, 'Questions people ask about the role of phonological processes in learning to read', Reading and Writing: An Interdisciplinary Journal 17, 483-515.

Share, D.L., 1995, 'Phonological recoding and self-teaching: Sine qua non of reading acquisition', Cognition 55(2), 219-226. https://doi.org/10.1016/0010-0277(94) 00645-2

Share, D.L., 2008, 'On the Anglocentricities of current reading research and practice: The perils of overreliance on an "outlier" orthography', Psychological Bulletin 134, 584-615. https://doi.org/10.1037/0033-2909.134.4.584

Simon, E. \& Van Herreweghe, M., 2010, 'The relation between orthography and phonology from different angles: Insights from psycholinguistics and second language acquisition', Language and Speech 53(3), 303-306. https://doi.org/ 10.1177/0023830910372486

Snowling, M. \& Hulme, C., 2005, The science of reading: A handbook, Blackwell, Oxford.

Spaull, N. \& Hoadley, U., 2017, 'Getting reading right', in L. Jamieson, L. Berry \& L. Lake (eds.), South African Child Gauge 2017, Children's Institute, University of Cape Town, Cape Town, pp. 77-83.

Stahl, S.A. \& Murray, B.A., 1994, 'Defining phonological awareness and its relationship to early reading', Journal of Educational Psychology 86, 221-234. https://doi. org/10.1037/0022-0663.86.2.221

Stanovich, K.E., Cunningham, A.E. \& Cramer, B.B., 1984, 'Assessing phonological awareness in kindergarten children: Issues of task comparability', Journal of $\mathrm{p}=\mathrm{rep} 1 \&$ type $=\mathrm{pdf}$

Taft, M. \& Forster, K.I., 1976, 'Lexical storage and retrieval of polymorphemic and polysyllabic words', Journal of Verbal Learning and Verbal Behavior 15, 607-620. polysyllabic words', Journal of Verbal Learning
https://doi/10.1016/0022-5371(76)90054-2

Tebekana, J. \& Cishe, E.N., 2015, 'Socio-cultural background factors affecting the Grade 3 learners' acquisition of English literacy (Reading) skills in Mthatha Education District of South Africa', International Journal of Educational Sciences 8(3), 557-562. https://doi.org/10.1080/09751122.2015.11890277

Tolchinsky, L. \& Jisa, H., 2017, 'Literacy development in Romance languages', in N. Kucirkova, C.E. Snow, V. Grover \& C. McBride (Eds.), The Routledge international handbook of early literacy education: A contemporary guide to literacy teaching in a global context, Chapter 9, Routledge, Oxford, NY.

Trask, R.L., 2004, What is a word?, Working Papers 11, Department of Linguistics and English Language, University of Sussex.

Truddell, B. \& Schroeder, L., 2007, 'Reading methodologies for African languages: Avoiding linguistic and pedagogic imperialism', Language, Culture and Curriculum 20(3), 165-180. https://doi.org/10.2167/lcc333.0

Van Staden, S. \& Bosker, R., 2014, 'Factors that affect South African reading literacy achievement: Evidence from pre PIRLS 2011', South African Journal of Education 34(3), 1-9. https://doi.org/10.15700/201409161059

Wilsenach, C., 2013, 'Phonological skills as predictor of reading success: An investigation of emergent Bilingual Northern Sotho/English Learners', Per investigation of emer.
Linguam 29, 17-32.

Ziegler, J., Bertrand, D., Toth, D., Csepe, V., Reis, A., Faisca, L. et al., 2010, 'Orthographic depth and its impact on universal predictors of reading: A cross-language
investigation', Psychological Science 21, 551-559. https//doi/10.1177/095679 investigation',

Ziegler, J.C. \& Goswami, U. 2005, 'Reading acquisition, developmental dyslexia, and skilled reading across languages: A psycholinguistic grain size theory', Psychological Bulletin 131(1), 3-29. https://doi/10.1037/0033-2909.131.1.3

Ziegler, J.C., Perry, C., Jacobs, A.M. \& Braun, M., 2001, 'Identical words are read differently in different languages', Psychological Science 12, 379-384. https://doi. org/10.1111/1467-9280.00370 